Case report

Perinatology Vol. 31, No. 2, June, 2020 https://doi.org/10.14734/PN.2020.31.2.99

\begin{abstract}
Ji Min Seo, MD', Shin Young Kim, MD', In Yang Park, MD, PhD', Hyojin Chae, MD, PhD ${ }^{2}$, Myungshin Kim, MD, PhD ${ }^{2}$

'Department of Obstetrics and Gynecology, College of Medicine, The Catholic University of Korea, Seoul; ${ }^{2}$ Department of Laboratory Medicine, Catholic Genetic Laboratory Center, Seoul St. Mary's Hospital, College of Medicine, The Catholic University of Korea, Seoul, Korea
\end{abstract}

Received: 19 August 2019

Revised: 27 January 2020

Accepted: 12 February 2020

Correspondence to In Yang Park, MD, PhD Department of Obstetrics and Gynecology, College of Medicine, The Catholic University of Korea, 222 Banpo-daero, Seocho-gu, Seoul 06591, Korea

Tel: +82-2-2258-6173

Fax: +82-2-595-1549

E-mail: ooooobbbbb@catholic.ac.kr

Copyright@ 2020 by The Korean Society of Perinatology

This is an Open Access article distributed under the terms of the Creative Commons Attribution Non-Commercial License (http://creativecommons.org/ license/by-nc/4.0/), which permits unrestricted non-commercial use, distribution, and reproduction in any medium, provided that the original work is properly cited.

\section{Prenatal Genetic Diagnosis of Congenital Nephrotic Syndrome}

Congenital nephrotic syndrome (CNS) of the Finnish type is an autosomal recessive disorder caused by mutations in the gene encoding nephrin (NPHS1). A 31-year-old primigravida woman from the Philippines was referred to Seoul St. Mary's Hospital with an abnormally elevated maternal serum a-fetoprotein (MSAFP) level of 8.5 multiples of the median (MoM) at 16+1 weeks gestation. The MSAFP level was 11.25 MoM when measured at Seoul St. Mary's Hospital. The amniotic fluid tested negative for acetylcholine esterase and had an a-fetoprotein level of $41.09 \mathrm{MoM}$. The karyotype was normal. Analysis of the NPHS1 gene in amniotic fluid by massively parallel sequencing revealed mutations associated with CNS. Cesarean delivery was performed at 37+4 weeks gestation due to transverse presentation. The neonate was not severely affected; there was no evidence of proteinuria or renal failure. However, because symptoms usually appear within 2 weeks to 1 month of age, close monitoring that includes regular blood and urine testing should be conducted.

Key Words: Fetus, Nephrotic syndrome, alpha-Fetoproteins, High-throughput nucleotide sequencing, Prenatal diagnosis

\section{Introduction}

Congenital nephrotic syndrome (CNS) of the Finnish type (CNF) is an autosomal recessive disorder caused by mutations in the gene encoding nephrin (NPHS1). ${ }^{1,2}$ It is the most common cause of CNS and is named for its high incidence in Finland of 1:8,200 live births. ${ }^{1,2}$ However, only a few cases have been reported in Korea. We report a case of CNS discovered by abnormally elevated maternal serum a-fetoprotein (MSAFP) and a prenatal genetic study. Nephrotic syndrome in the neonate can cause significant morbidity and mortality; therefore, if possible, urgent prenatal diagnosis and management are necessary. ${ }^{2}$

\section{Case}

A 31-year-old primigravida woman from the Philippines was referred to Seoul St. Mary's Hospital at $17+1$ weeks gestation with an abnormally elevated MSAFP level of 8.5 multiples of the median $(\mathrm{MoM})$ at $16+1$ weeks gestation. The results of the integrated test performed in the second trimester revealed high risk for Down syndrome but low risk for Edward syndrome. She had no family history of any disease, and her husband is Korean without specific familial disease history. Until then, the patient's antenatal examination had been unremarkable. The thickness of the nuchal translucency was within the normal limit of $1.6 \mathrm{~mm}$, and no structural anomalies were observed on routine prenatal ultrasonography examination. The MSAFP level was at 11.25 MoM when measured at Seoul St. Mary's Hospital. The amniotic fluid tested negative for acetylcholine esterase and had an a-fetoprotein level of 41.09 MoM. The karyotype was normal (Table 1). Neural tube defect and chromosomal 
Table 1. Results of the Antenatal Test for the Patient

\begin{tabular}{|c|c|c|}
\hline Gestational week & Tests & Results \\
\hline \multirow[t]{2}{*}{$12+1$} & Nuchal translucency & $1.6 \mathrm{~mm}$ \\
\hline & Pregnancy-associated plasma protein A & $0.392 \mathrm{MoM}$ \\
\hline \multirow[t]{4}{*}{$16+1$} & Maternal serum a-fetoprotein & $8.520 \mathrm{MoM}$ \\
\hline & Human chorionic gonadotropin & $3.526 \mathrm{MoM}$ \\
\hline & Unconjugated estriol & $0.818 \mathrm{MoM}$ \\
\hline & Inhibin A & $7.047 \mathrm{MoM}$ \\
\hline $17+1$ & Maternal serum a-fetoprotein & $11.246 \mathrm{MoM}$ \\
\hline \multirow[t]{4}{*}{$18+1$} & Amniotic fluid a-fetoprotein & 41.09 MoM \\
\hline & Amniotic fluid acetylcholine esterase & Not detected \\
\hline & Karyotyping by amniocentesis & Normal \\
\hline & Analysis of the NPHS1 gene in amniotic fluid & Detected \\
\hline
\end{tabular}

Abbreviations: MoM, multiples of the median; NPHS1, mutations in the gene encoding nephrin.

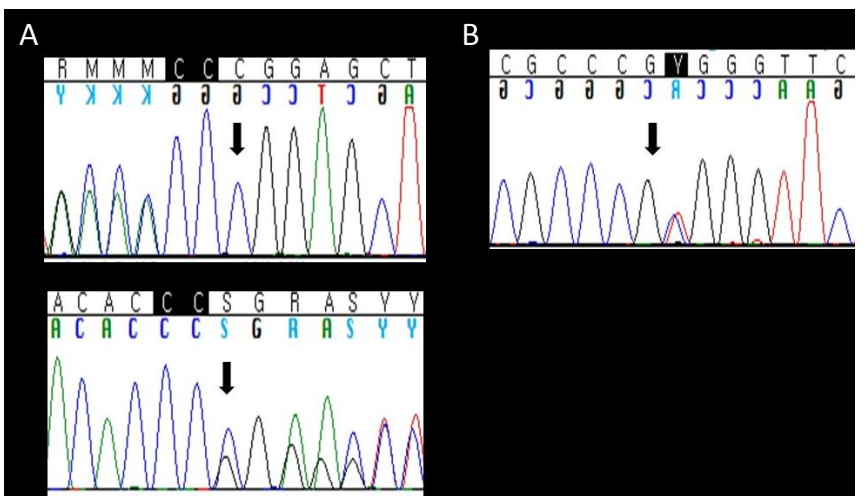

Fig. 1. Sequencing chromatogram of the CNS proband. Sequence analysis of the proband and parents demonstrated c.619del (A) and c.1105C >T (B) of the NPHS1 gene. CNS, congenital nephrotic syndrome; NPHS1, mutations in the gene encoding nephrin.

abnormalities, including Down syndrome, were excluded, and CNS was suspected. Analysis of the NPHS1 gene in the amniotic fluid by massively parallel sequencing revealed a previously reported frameshifting deletion mutation in exon 6 (c.619del, p.Arg207Glyfs*28) ${ }^{3}$ and a previously reported missense mutation in exon 9 (c.1105C>T, pArg369Trp), which are causative mutations of CNS (Fig. 1). Compound heterozygosity was confirmed by sanger sequencing of the parents: the mother and the father harbored c.619del and c.1105C>T, respectively. Therefore, the prenatal diagnosis was consistent with CNS.

Until term, follow-up and level II ultrasonography examinations did not reveal any congenital anomalies (e.g., fetal hydrops). Cesarean delivery was performed at $37+4$ weeks gestation because of transverse presentation of the fetus. A live baby girl weighing 2,730 g was delivered with Apgar scores of 7 and 8 at 1 and 5 minutes, respectively. The accessory placenta was noted; however, placentomegaly was not observed as the placenta weighed $500 \mathrm{~g}$. The neonate was not edematous and urinated well with no sign of proteinuria. The serum levels of creatinine, blood urea nitrogen, albumin, and electrolytes were normal. The laboratory tests for toxoplasma, rubella, cytomegalovirus, and herpes simplex virus infections were all negative.

The postnatal abdominal ultrasonography examination showed no definite abnormalities in either the kidneys or liver. Followup blood and urine tests were conducted until the neonate was 3 months old. The test results were normal, with no indication of proteinuria, hypoalbuminemia, or renal failure, and no edema were observed in the neonate. Regular check-ups and close monitoring will be performed continuously.

\section{Discussion}

Nephrotic syndrome (NS) is defined as massive leakage of plasma proteins into the urine that results in hypoalbuminemia and edema. It is caused by disruption of the glomerular filtration barrier. ${ }^{2,45}$ NS is classified by age at presentation: CNS, age at presentation <3 months), infantile NS (age at presentation 3-12 months), or childhood NS (age at presentation $>1$ year). ${ }^{2}$ Different mutations in the same gene express the disease at various ages. $^{4,5}$

$\mathrm{CNF}$ is the leading cause of $\mathrm{CNS}$ and has a high incidence in Finland of 1:8,200 live births. ${ }^{6} \mathrm{CNF}$ is an autosomal recessive disease caused by mutations in the gene; nephrosis 1, congenital, Finnish type (NPHS1), NS encoding nephrin, which is the major structural component of the glomerular slit diaphragm. ${ }^{2,7}$ Detection rate of this gene mutation varies among ethnic groups. ${ }^{8}$ It is up to $98 \%$ in Finish children with $\mathrm{CNS}^{7}{ }^{7}$ however, no case has been reported in the Philippines, and only a few have been reported in Korea. ${ }^{9,10}$ In this case, the baby's mother is from the Philippines, and her husband is Korean.

CNF can often be diagnosed on a clinical basis and is characterized by prematurity, a large placenta, and massive proteinuria that may begin in utero. ${ }^{11,12}$ More than $80 \%$ of infants with CNF are born prematurely, with appropriate birth weight for gestational age. ${ }^{11,12}$ A large placenta is a common finding, weighing more 
than $25 \%$ of the infant's birth weight. ${ }^{2,11}$ About $80 \%$ of affected infants demonstrate edema and other signs of NS within the first week of life, with others presenting within 3 months. ${ }^{12}$ Severe hypoalbuminemia is present with a serum albumin concentration generally $<1.5 \mathrm{mg} / \mathrm{dL}^{2}{ }^{2}$ Typically, renal function is initially normal, and kidney function disruption presents over several years. ${ }^{2}$ A kidney biopsy is rarely necessary for diagnosis of $\mathrm{CNF}^{2}{ }^{2} \mathrm{De}-$ tection of mutations in NPHS1 can confirm diagnosis of CNF. More than 80 mutations in NPHS1 have been identified in affected patients. ${ }^{13}$ Mutations have been found throughout all 29 exons. $^{13,14}$

Elevated MSAFP level obtained in a routine second-trimester screening is a suspicious finding for $\mathrm{CNS}^{2}$ It is common and is found in approximately $1 \%$ of all pregnancies using a cutoff of $>2.5 \mathrm{MoM}^{2}$ Increased MSAFP can be seen in pregnancies with neural tube defects, gastroschisis, or chromosomal abnormalities as well as $\mathrm{CNS}^{15,16} \mathrm{CNS}$ is a rare cause of elevated MSAFP, with a retrospective study identifying only five infants with CNS among 658 women with elevated MSAFP $(<1 \%) .{ }^{16}$ Most pregnancies complicated with CNS show persistently elevated MSAFP on follow-up tests and elevated a-fetoprotein in amniotic fluid obtained by amniocentesis. ${ }^{16}$ Median MSAFP concentration was 8.3 MoM in pregnancies affected by CNS due to NPHS1 mutation, while median a-fetoprotein concentration in amniotic fluid was much higher at 33.4 MoM. ${ }^{17}$ Brady et al. ${ }^{18}$ suggested that MSAFP values peak between 19 and 21 weeks and then decline in NPHS1 carrier pregnancies, whereas values remain elevated in affected pregnancies. However, limited information is available on the gestational age range of this peak and decline of MSAFP value for carrier pregnancies.

The treatment is generally supportive and includes massive intravenous albumin infusion, close monitoring of neonate growth, hypercaloric diet with added protein, and infection prevention. ${ }^{1,2,11}$ Bilateral nephrectomies are performed when children are nearing end-stage kidney disease or if the CNS cannot be managed with medical treatment, usually at 1-3 years old. ${ }^{2,11}$

In the present case, the pregnant woman presented with abnormally elevated MSAFP that was determined by integrated test performed at the second trimester. The patient is from the Philippines, and her husband is Korean. Both had no family history of nephropathy including nephrotic syndrome. Through amniocentesis and ultrasonography examination, neural tube defect and chromosomal abnormalities were excluded from the diagnosis. Follow-up tests at $18+1$ weeks of gestation showed persistent, abnormally elevated MSAFP and amniotic fluid $a^{-}$ fetoprotein levels. Further evaluation for detection of mutations in the NPHS1 gene in the amniotic fluid demonstrated causative mutations of CNS; frameshifting deletion mutation in exon 6 (c.619del, p.Arg207Glyfs*28) and missense mutation in exon 9 (c.1105C>T, pArg369Trp). The compound heterozygosity was confirmed, and each parent contributed one mutation. In compound heterozygous forms, some autosomal recessive diseases like hemochromatosis may have lower penetrance because the mutations involved are often less deleterious in combination than for a homozygous individual with the classic symptoms of the disease. ${ }^{19}$ In this case, the neonate did not show any definite symptoms or signs of NS, such as edema, proteinuria, or decreased kidney function. However, close monitoring of infant growth and regular blood and urine tests were performed with nutritional support but without medicine.

Although not observed for this case, CNS in the neonate can cause significant morbidity, resulting in kidney transplantation and mortality in many cases. Fortunately, some mutations in the gene expressing CNS have been revealed. Different mutations in the same gene express the disease at various ages with different penetrance. Therefore, prenatal diagnosis of CNS using genetic tests can help to evaluate and manage affected neonates after birth.

\section{Conflict of interest}

No potential conflict of interest relevant to this article was reported.

\section{References}

1) Kestilä $M$, Järvelä I. Prenatal diagnosis of congenital nephrotic syndrome (CNF, NPHS1). Prenat Diagn 2003;23:323-4.

2) Rheault MN. Nephrotic and nephritic syndrome in the newborn. Clin Perinatol 2014;41:605-18.

3) Machuca E, Benoit G, Nevo F, Tête MJ, Gribouval O, Pawtowski A, et al. Genotype-phenotype correlations in non-Finnish congenital nephrotic syndrome. J Am Soc Nephrol 2010;21:1209-17. 
4) Santín S, García-Maset R, Ruíz P, Giménez I, Zamora I, Peña A, et al. Nephrin mutations cause childhood- and adult-onset focal segmental glomerulosclerosis. Kidney Int 2009;76:1268-76.

5) Hinkes B, Vlangos C, Heeringa S, Mucha B, Gbadegesin R, Liu J, et al. Specific podocin mutations correlate with age of onset in steroidresistant nephrotic syndrome. J Am Soc Nephrol 2008;19:365-71.

6) Huttunen NP. Congenital nephrotic syndrome of Finnish type. Study of 75 patients. Arch Dis Child 1976;51:344-8.

7) Kestilä M, Lenkkeri U, Männikkö M, Lamerdin J, McCready P, Putaala H, et al. Positionally cloned gene for a novel glomerular protein--nephrin-is mutated in congenital nephrotic syndrome. Mol Cell 1998;1:575-82.

8) Spahiu L, Merovci B, Jashari H, Këpuska AB, Rugova BE. Congenital nephrotic syndrome - finish type. Med Arch 2016;70:232-4.

9) Lee BH, Ahn YH, Choi HJ, Kang HK, Kim SD, Cho BS, et al. Two Korean infants with genetically confirmed congenital nephrotic syndrome of Finnish type. J Korean Med Sci 2009;24 Suppl 1:210-4.

10) Lee JH, Han KH, Lee H, Kang HG, Moon KC, Shin Jl, et al. Genetic basis of congenital and infantile nephrotic syndromes. Am J Kidney Dis 2011;58: 1042-3.

11) Yoshizawa C, Kobayashi Y, Ikeuchi Y, Tashiro M, Kakegawa S, Watanabe $T$, et al. Congenital nephrotic syndrome with a novel NPHS1 mutation. Pediatr Int 2016:58:1211-5.

12) Patrakka J, Kestilä M, Wartiovaara J, Ruotsalainen $V$, Tissari $P$, Lenkkeri $U$, et al. Congenital nephrotic syndrome (NPHS1): features resulting from different mutations in Finnish patients. Kidney Int 2000;58:972-80.

13) Heeringa SF, Vlangos CN, Chernin G, Hinkes B, Gbadegesin R, Liu J, et al. Thirteen novel NPHS1 mutations in a large cohort of children with congenital nephrotic syndrome. Nephrol Dial Transplant 2008;23:352733.

14) Beltcheva O, Martin P, Lenkkeri U, Tryggvason K. Mutation spectrum in the nephrin gene (NPHS1) in congenital nephrotic syndrome. Hum Mutat 2001;17:368-73.

15) Muller F, Forestier F, Dingeon B; ABA Study Group. Second trimester trisomy 21 maternal serum marker screening. Results of a countrywide study of 854,902 patients. Prenat Diagn 2002;22:925-9.

16) Spaggiari E, Ruas M, Dreux S, Valat AS, Czerkiewicz I, Guimiot F, et al. Management strategy in pregnancies with elevated second-trimester maternal serum alpha-fetoprotein based on a second assay. Am J Obstet Gynecol 2013;208:303.e1-7.

17) Patrakka J, Martin P, Salonen R, Kestilä M, Ruotsalainen V, Männikkö M, et al. Proteinuria and prenatal diagnosis of congenital nephrosis in fetal carriers of nephrin gene mutations. Lancet 2002;359:1575-7.

18) Brady TB, Mitra AG, Hooks J. Maternal serum alpha-fetoprotein levels peak at 19-21 weeks' gestation and subsequently decline in an NPHS1 sequence variant heterozygote; implications for prenatal diagnosis of congenital nephrosis of the Finnish type. Prenat Diagn 2014;34:812-4.

19) Waalen J, Nordestgaard BG, Beutler E. The penetrance of hereditary hemochromatosis. Best Pract Res Clin Haematol 2005;18:203-20. 